\title{
PENINGKATAN KUALITAS LAYANAN WEBSITE MANAJEMEN TUGAS AKHIR DENGAN MEMANFAATKAN METODE WEBQUAL 4.0 DAN IPA
}

\author{
Adi Pratomo'), Agus Irawan' ${ }^{2)}$, Mey Risa ${ }^{3)}$ \\ ${ }^{1,2}$ Manajemen Informatika, ${ }^{3}$ Administrasi Bisnis, \\ Politeknik Negeri Banjarmasin \\ Email : $\underline{\text { adipratomo@poliban.ac.id, agusvp@ymail.com, meyrisa@poliban.ac.id }}$
}

\begin{abstract}
Abstrak- Website merupakan sebuah media yang saat ini banyak dipergunakan sebagai alat untuk memberikan pelayanan dan informasi. Jurusan Administrasi Bisnis Politeknik Negeri Banjarmasin saat ini telah mempergunakan website untuk berbagai keperluan, diantaranya adalah untuk mengelola pelaksanaan tugas akhir mahasiswa. Sistem informasi pengelolaan tugas akhir mahasiswa telah dipergunakan selama tiga tahun, namun sejak awal dijalankan yaitu pada tahun 2015 website sistem informasi tugas akhir belum pernah dilakukan evaluasi sehingga tidak diketahui bagaimana kualitas, tampilan dan fungsi website tersebut dari persepsi penggunanya. Informasi ini sangat dibutuhkan untuk melakukan perbaikan sistem yang saat ini telah berjalan berdasarkan persepsi pengguna. Penelitian ini bertujuan untuk menganalisis kualitas website manajemen tugas akhir berdasarkan metode WebQual dengan dimensi Usability, Information, dan Service Interaction serta metode Importance-Performance Analysis (IPA) dengan pendekatan metode penelitian deskriptif kuantitatif. Analisa diukur berdasarkan tingkat kinerja (performance) dan tingkat kepentingan (importance), dimana didapatkan hasil kesenjangan atau gap secara keseluruhan untuk semua dimensi dan total rata-rata. Nilai kesenjangan terbesar terdapat pada dimensi service interaction. Berdasarkan hal tersebut dapat disimpulkan bahwa website manajemen tugas akhir secara aktual dirasakan belum memenuhi kualitas ideal terutama yang berhubungan dengan service interaction. Hasil analisa selanjutnya dipergunakan sebagai acuan perbaikan sistem yang menekankan pada peningkatan faktor interaksi yang lebih jelas dan dapat dimengerti, kemudahan navigasi, perbaikan tampilan, kemudahan dipelajari dan dioperasikan.
\end{abstract}

\section{Kata kunci : Importance-Performance Analysis; Kualitas; Website; WebQual}

\section{PENDAHULUAN}

Website merupakan sebuah media yang saat ini banyak dipergunakan sebagai alat untuk memberikan pelayanan dan informasi. Jurusan Administrasi Bisnis saat ini telah mempergunakan website untuk berbagai keperluan, diantaranya adalah untuk mengelola pelaksanaan tugas akhir mahasiswa. Sistem informasi pengelolaan tugas akhir mahasiswa telah dipergunakan selama tiga tahun, namun sejak awal dijalankan yaitu pada tahun 2015 website sistem informasi tugas akhir belum pernah dilakukan evaluasi website sehingga pihak jurusan administrasi bisnis tidak mengetahui bagaimana kualitas website tersebut menurut penggunanya serta adanya kritik dari pengguna mengenai tampilan website yang tidak menarik dan beberapa fitur yang tidak efektif. Informasi ini sangat dibutuhkan untuk melakukan perbaikan sistem yang saat ini telah berjalan berdasarkan persepsi pengguna.

Webqual merupakan suatu metode untuk pengukuran kualitas website yang berdasarkan pada persepsi pengguna akhir. Metode ini sudah banyak digunakan untuk pengukuran kualitas jasa dan merupakan salah satu pengembangan dari metode servqual. Metode webqual memiliki instrumen penelitian yang dikembangkan denngan metode Quality Function Development (QFD).
Berdasarkan pada penelitian Barnes dan Vigen (2003) yang mengukur kualitas website yang dikelola oleh OECD (Organization for Economic Cooperation and Development) menggunakan metode webqual 4.0 dihasilkan tiga area atau dimensi pada metode webqual 4.0 yaitu dimensi kualitas informasi, dimensi kualitas Interkasi, dimensi kualitas usability.

Untuk mengidentifikasi faktor apa saja dari website yang harus ditingkatkan kinerjanya untuk memenuhi kepuasan pengguna, dapat dipergunakan Importance Performance Analysis Method (IPA). Metode IPA pertama kali dikenalkan oleh John A. Martilla dan John C. James pada tahun 1997 sebagai sebuah teknik analisis deskriptif[9].

Pengukuran persepsi pengguna akhir terhadap kualitas website sistem informasi tugas akhir mahasiswa akan menggunakan penggabungan metode webqual 4.0 dan IPA, dimana dari hasil webqual 4.0 tersebut selanjutnya dapat diidentifikasi dimensi-dimensi kunci dan aspek-aspek dalam setiap dimensi website yang membutuhkan penyempurnaan kualitas berdasarkan persepsi (actual-performance) dan harapan pengguna (ideal-performance). Prioritas perbaikan kualitas dan atribut yang tidak menjadi 
prioritas perbaikan nantinya dapat dilihat dari kuadran IPA.

\section{METODE PENELITIAN}

Penelitian yang dilakukan dimasukkan ke dalam kategori penelitian deskriptif kuantitatif. Variabel-variabel yang digunakan pada penelitian ini adalah berdasarkan pada metode WEBQUAL versi 4.0 berdasarkan penelitian yang dilakukan oleh Barnes dan Vidgen yang terdiri dari usability, information, dan service interaction dimana terdiri dari 22 total indikator yang dapat dibedakan menjadi dua jenis, yaitu kualitas yang saat ini dirasakan atau aktual terjadi yang disebut dengan (Performance) dan kualitas yang diharapkan dan dianggap penting untuk dikembangkan yang disebut dengan (Importance). Variabel penilaian yang menjadi indikator pada penelitian ini dapat dilihat pada Tabel 1 dibawah ini.

Tabel 1 Variabel penilaian indikator penelitian

\begin{tabular}{|c|c|c|}
\hline Kategori & Indikator & $\begin{array}{c}\text { Kode } \\
\text { Variabel }\end{array}$ \\
\hline \multirow{8}{*}{ Usability } & $\begin{array}{l}\text { Interaksi jelas dan dapat } \\
\text { dimengerti }\end{array}$ & USA1 \\
\hline & Mudah melakukan navigasi & USA2 \\
\hline & Tampilan menarik & USA3 \\
\hline & Desain sesuai & USA4 \\
\hline & Daya saing & USA5 \\
\hline & $\begin{array}{l}\text { Mudah dipelajari dan } \\
\text { dioperasikan }\end{array}$ & USA6 \\
\hline & Mudah digunakan & USA7 \\
\hline & Pengalaman positif & USA8 \\
\hline \multirow{7}{*}{ Information } & Informasi akurat & INF1 \\
\hline & Informasi dapat dipercaya & INF2 \\
\hline & Informasi aktual & INF3 \\
\hline & Informasi relevan & INF4 \\
\hline & $\begin{array}{l}\text { Informasi mudah } \\
\text { dimengerti }\end{array}$ & INF5 \\
\hline & $\begin{array}{l}\text { Informasi dengan tingkat } \\
\text { detail yang tepat }\end{array}$ & INF6 \\
\hline & $\begin{array}{l}\text { Informasi dalam format } \\
\text { yang sesuai }\end{array}$ & INF7 \\
\hline \multirow{7}{*}{$\begin{array}{l}\text { Service } \\
\text { Interaction }\end{array}$} & Reputasi baik & SERV1 \\
\hline & $\begin{array}{l}\text { Keamanan dalam } \\
\text { bertransaksi }\end{array}$ & SERV2 \\
\hline & $\begin{array}{l}\text { Keamanan informasi } \\
\text { pribadi }\end{array}$ & SERV3 \\
\hline & Ruang personalisasi & SERV4 \\
\hline & $\begin{array}{l}\text { Pelaksanaan layanan sesuai } \\
\text { janji }\end{array}$ & SERV5 \\
\hline & $\begin{array}{l}\text { Kemudahan berkomunikasi } \\
\text { dengan perusahaan }\end{array}$ & SERV6 \\
\hline & Rasa komunitas & SERV7 \\
\hline
\end{tabular}

\subsection{Sampel}

Metode pengambilan sampel dalam penelitian ini adalah purposive random sampling. Pengambilan sampel dengan cara ini merupakan teknik pengambilan sampel secara acak dengan pertimbangan tertentu. Sampel dalam penelitian ini adalah dosen dan mahasiswa di Jurusan administrasi bisnis Politeknik Negeri Banjarmasin berjumlah 100 orang, dimana 20 orang dipergunakan untuk menguji validitas dan reliabilitas. Sedangkan 80 orang lainnya dipergunakan untuk analisa data webqual dan IPA.

\subsection{Teknik Pengumpulan Data}

Teknik pengumpulan data menggunakan metode survei dengan menyebarkan kuesioner kepada responden yaitu mahasiswa di Jurusan Administrasi Bisnis Politeknik Negeri Banjarmasin. Peneliti melakukan penyebaran kuesioner dengan cara menyebarkan kuesioner online yang disebar di web sista, beberapa forum dan media sosial yang dianggap sebagai tempat yang sesuai untuk mendapatkan responden dengan karakteristik sampel yang ditetapkan untuk penelitian ini serta dengan menyebarkan kuesioner secara langsung di lokasi kampus untuk menjaring responden mahasiswa dengan lebih sesuai target.

\subsection{Teknik Skala Penelitian}

Teknik yang digunakan dalam pengambilan sampel yang dilakukan pada penelitian ini adalah judgement sampling yang diukur berdasarkan enam (6) skala mulai dari sangat tidak setuju sampai sangat setuju. Pemilihan skala likert satu sampai enam (1 - 6) dipilih untuk mengurangi risiko penyimpangan pengambilan keputusan pribadi dan mempunyai kehandalan yang tinggi dengan menghilangkan skala netral atau neutral [3]

\subsection{Uji Validitas dan Reliabilitas}

Pengujian validitas dan realibilitas dari kuesioner yang dilakukan pada penelitian ini mengambil sampel 20 kuesioner yang telah diisi oleh responden. Uji validitas menggunakan nilai $r$ tabel dengan signifikansi 0,05 . Untuk nilai $r$ tabel dengan $n=20$ maka di dapat $r$ tabel sebesar 0.4438 , jadi jika nilai korelasi lebih dari nilai $r$ tabel maka item dianggap valid, sedangkan jika kurang dari batasan yang ditentukan maka item dianggap tidak valid. 
Tabel 2 Uji validitas

\begin{tabular}{l|c|c|c}
\hline \multicolumn{1}{c}{ r hitung } & r tabel & Keterangan \\
\hline USA1 &, 882 & 0.4438 & Valid \\
USA2 &, 864 & 0.4438 & Valid \\
USA3 &, 712 & 0.4438 & Valid \\
USA4 &, 852 & 0.4438 & Valid \\
USA5 &, 926 & 0.4438 & Valid \\
USA6 &, 848 & 0.4438 & Valid \\
USA7 &, 822 & 0.4438 & Valid \\
USA8 &, 886 & 0.4438 & Valid \\
INF1 &, 909 & 0.4438 & Valid \\
INF2 &, 909 & 0.4438 & Valid \\
INF3 &, 875 & 0.4438 & Valid \\
INF4 &, 913 & 0.4438 & Valid \\
INF5 &, 877 & 0.4438 & Valid \\
INF6 &, 836 & 0.4438 & Valid \\
INF7 &, 892 & 0.4438 & Valid \\
SERV1 &, 862 & 0.4438 & Valid \\
SERV2 &, 870 & 0.4438 & Valid \\
SERV3 &, 903 & 0.4438 & Valid \\
SERV4 &, 926 & 0.4438 & Valid \\
SERV5 &, 926 & 0.4438 & Valid \\
SERV6 &, 835 & 0.4438 & Valid \\
SERV7 &, 788 & 0.4438 & Valid \\
\hline \multicolumn{1}{c}{ Sumber } & $:$ Data primer yang diolah, Tahun 2018
\end{tabular}

Uji reliabilitas yang digunakan pada penelitian ini yaitu menggunakan metode Cronbach Alpha. Apabila didapatkan nilai Croanbach's Alpha kurang dari 0,600 berarti buruk, sekitar 0,700 diterima dan lebih dari atau sama dengan 0,800 adalah baik. Hasil pengujian reliabilitas didapat Cronbachs Alpha .985, sehingga instrument yang dipergunakan telah memenuhi kriteria reliabilitas dan merupakan alat ukur yang dapat dipercaya, handal dan siap untuk dipergunakan.

Tabel 3 Reliability Statistics

\begin{tabular}{r|r|r}
\hline $\begin{array}{c}\text { Cronbach's } \\
\text { Alpha }\end{array}$ & $\begin{array}{c}\text { Cronbach's } \\
\text { Alpha Based } \\
\text { on } \\
\text { Standardized } \\
\text { Items }\end{array}$ & N of Items \\
\hline, 985 &, 986 & 22 \\
\hline \multicolumn{2}{c}{ Sumber : Data primer yang diolah, Tahun 2018 }
\end{tabular}

\subsection{Alat Analisis Data}

Hasil pengumpulan data yang diperoleh melalui kuesioner yang disebarkan kepada mahasiswa jurusan Administrasi Bisnis akan dianalisis dengan menggunakan metode Importance Performance Analysis (IPA). Analisis IPA dilakukan dengan melakukan analisis kesesuaian, analisis kesenjangan dan analisis kuadran IPA.

\subsection{Analisis Kesesuaian}

Analisis kesesuaian digunakan untuk mengetahui perbandingan skor kinerja website dengan skor kepentingan website. Hasil dari analisis kesesuaian ini menunjukkan apakah kinerja website sudah sesuai dengan kepentingan atau harapan pengguna. Analisis kesesuaian dapat dilakukan dengan perhitungan sebagai berikut :

$$
T k i=\frac{x i}{y i} x 100 \%
$$

Keterangan :

$T k i=$ tingkat kesesuaian responden

$x i=$ skor penilaian kinerja

$y i=$ skor penilaian kepetingan

Kriteria penilaian tingkat kesesuaian pelanggan atau pengguna :

1. Tingkat kesesuaian pengguna $>100 \%$, berarti kualitas layanan yang diberikan telah melebihi apa yang dianggap penting oleh pengguna, berarti Pelayanan sangat memuaskan

2. Tingkat kesesuaian pengguna $=100 \%$, berarti kualitas layanan yang diberikan memenuhi apa yang dianggap penting oleh pengguna berarti Pelayanan telah memuaskan

3. Tingkat kesesuaian $<100 \%$ berarti kualitas layanan yang diberikan kurang/tidak memenuhi apa yang dianggap penting oleh pengguna berarti Pelayanan belum memuaskan.

\subsection{Analisis Kesenjangan (GAP)}

Analisis kesenjangan adalah pendekatan inovatif dan berguna untuk melakukan penilaian kebutuhan dan untuk mengevaluasi program. Analisis dapat digunakan untuk mengukur perbedaan antara kepuasan pengguna dengan kinerja atau aktual website. Untuk melakukan analisis kesenjangan skor rata-rata kinerja dan skor rata-rata kepentingan dari setiap atribut dihitung. Kemudian skor rata-rata kinerja dikurangi dengan skor rata-rata kepentingan seperti pada rumus dibawah ini :

$$
Q i(G a p)=\operatorname{Per} f(i)-\operatorname{Imp}(i)(2)
$$

Keterangan :

$Q i($ Gap $)=$ tingkat kesenjangan

$\operatorname{Perf}(i)=$ rata-rata kinerja

$\operatorname{Imp}(i)=$ rata-rata kepentingan

Dari hasil perhitungan tersebut nantinya dapat dilihat jika hasilnya menunjukkan positif atau Qi (GAP) > 0 maka kinerja sistem sudah sesuai dengan kepentingan atau harapan pengguna. Namun jika hasil perhitungan menunjukkan negatif atau Qi (GAP) < 0 maka kinerja sistem saat ini tidak sesuai dengan harapan pengguna.

\subsection{Analisis Kuadran IPA}

IPA menggabungkan pengukuran faktor tingkat kepentingan dan tingkat kepuasan dalam grafik dua dimensi yang memudahkan penjelasan data dan mendapatkan usulan praktis. 
Interpretasi grafik IPA sangat mudah, dimana grafik IPA dibagi menjadi empat buah kuadran berdasarkan hasil pengukuran importanceperformance. Mengenai metode IPA bahwa atribut performance digambarkan sepanjang sumbu-X dan atribut importance (kepuasan dan kualitas pelayanan) digambarkan sepanjang sumbu-Y [9]. Berikut penjelasan untuk masingmasing kuadran [9]:

1. Kudran pertama:

Tingkatkan Kinerja (high importance dan low performance). Dianggap faktor yang sangat penting namun belum memuaskan untuk kondisi saat ini sehingga harus menjadi perhatian bagi manajemen untuk mengalokasikan sumber daya yang memadai.

2. Kuadran kedua:

Pertahankan Kinerja (high importance dan high perfomance). Dianggap sebagai faktor penunjang bagi kepuasan konsumen sehingga manajemen wajib memastikan kinerja institusinya dapat mempertahankan prestasi yang telah dicapai.

3. Kuadran ketiga:

Prioritas rendah (low importance dan low performance). Dianggap mempunyai tingkat kepuasan yang rendah sekaligus dianggap tidak terlalu penting oleh konsumen, sehingga manajemen tidak perlu memprioritaskan faktor tersebut.

4. Kuadran keempat:

Cenderung Berlebihan (low importance dan high performance). Dianggap tidak terlalu penting sehingga manajemen bisa mengalokasikan sumber daya yang terkait dengan faktor-faktor tersebut kepada faktor-faktor lain yang lebih membutuhkan peningkatan penanganan.

Berikut ini adalah penggambaran dari pembagian kuadran yang terdapat pada IPA yang dapat dilihat pada gambar 1 dibawah ini.

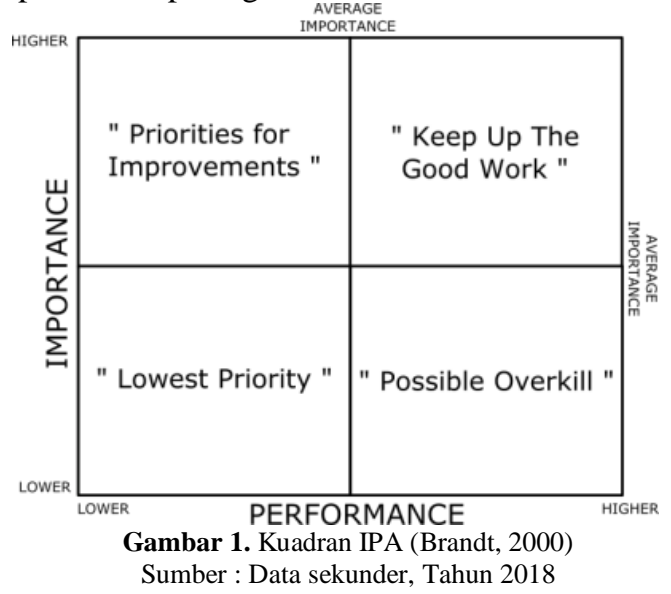

\section{HASIL DAN PEMBAHASAN}

Pada penelitian ini dipergunakan populasi sebanyak 100 orang. 20 orang dipergunakan sebagai sampel, sehingga 80 orang sisanya merupakan responden yang dipergunakan untuk pengukuran. Responden mengisi kuesioner yang berisi 22 item pertanyaan, dimana untuk setiap pertanyaan dibagi menjadi penilaian terhadap kinerja (performance) sistem saat ini dan penilaian terhadap harapan pengguna terhadap sistem.

Berikut ini adalah Tabel 3 yang menggambarkan dari dimensi indikator yang digunakan dalam penelitian ini setelah dilakukan uji validitas dan uji realibilitas berserta dengan nilai kinerja dan harapan.

Tabel 4 Nilai rata rata pembobotan indikator

\begin{tabular}{|c|c|c|c|}
\hline & Kinerja & Harapan & $\mathrm{N}$ \\
\hline USA1 & 4,28 & 4,40 & 80 \\
\hline USA2 & 4,30 & 4,36 & 80 \\
\hline USA3 & 4,41 & 4,51 & 80 \\
\hline USA4 & 4,69 & 4,78 & 80 \\
\hline USA5 & 4,46 & 4,55 & 80 \\
\hline USA6 & 4,55 & 4,63 & 80 \\
\hline USA7 & 4,24 & 4,39 & 80 \\
\hline USA8 & 4,54 & 4,63 & 80 \\
\hline INF1 & 4,48 & 4,55 & 80 \\
\hline INF2 & 4,66 & 4,74 & 80 \\
\hline INF3 & 3,89 & 4,01 & 80 \\
\hline INF4 & 4,41 & 4,50 & 80 \\
\hline INF5 & 4,73 & 4,80 & 80 \\
\hline INF6 & 4,66 & 4,73 & 80 \\
\hline INF7 & 4,30 & 4,36 & 80 \\
\hline SERV1 & 4,84 & 4,89 & 80 \\
\hline SERV2 & 4,61 & 4,64 & 80 \\
\hline SERV3 & 4,56 & 4,63 & 80 \\
\hline SERV4 & 4,38 & 4,41 & 80 \\
\hline SERV5 & 2,18 & 3,81 & 80 \\
\hline SERV6 & 2,53 & 4,09 & 80 \\
\hline SERV7 & 4,61 & 4,63 & 80 \\
\hline Rata Rata & 4,286 & 4,501 & \\
\hline
\end{tabular}

Hasil analisis tingkat kesesuaian pada website manajemen tugas akhir jurusan administrasi bisnis Politeknik Negeri Banjarmasin didapatkan dari perbandingan setiap atribut penilaian kinerja dengan atribut penilaian kepentingan dan hasilnya diprosentasikan. Hasil akhir rata-rata tingkat kesesuaian pada website adalah 95,22\% dan masih dibawa $100 \%$. Artinya tingkat kinerja dan layanan website manajemen tugas akhir jurusan Administrasi Bisnis Politeknik Negeri Banjarmasin masih berada dibawah ekspetasi pengguna.

Analisis kesenjangan (gap) dilakukan untuk melihat tingkat kualitas dari website yang ditinjau dari nilai kesenjangan (gap) antara kualitas/kinerja yang dirasakan (aktual) dan kualitas/kinerja yang diharapkan (ideal). Tingkat kualitas yang baik ditandakan dengan nilai positif atau Qi (gap) >0. Sebaliknya bila hasil Qi (gap) $<0$ atau bernilai negatif, maka tingkat kualitas dinyatakan kurang dan belum dapat memenuhi keinginan ideal dari pengguna. Penjelasan kesenjangan dimensi indikator kualitas diuraikan 
dalam masing-masing dimensi yaitu usability, information dan service interaction.

Tabel 5 Nilai Gap Usability

\begin{tabular}{|c|c|c|c|}
\hline & $\begin{array}{c}\text { Kinerja } \\
\text { (Performance) }\end{array}$ & $\begin{array}{c}\text { Harapan } \\
\text { (Importance) }\end{array}$ & GAP \\
\hline USA1 & 4,28 & 4,4 & $-0,12$ \\
\hline USA2 & 4,3 & 4,36 & $-0,06$ \\
\hline USA3 & 4,41 & 4,51 & $-0,10$ \\
\hline USA4 & 4,69 & 4,78 & $-0,09$ \\
\hline USA5 & 4,46 & 4,55 & $-0,09$ \\
\hline USA6 & 4,55 & 4,63 & $-0,08$ \\
\hline USA7 & 4,24 & 4,39 & $-0,15$ \\
\hline USA8 & 4,54 & 4,63 & $-0,09$ \\
\hline Rata Rata & 4,43 & 4,53 & $-0,10$ \\
\hline
\end{tabular}

Tabel diatas menunjukan nilai kesenjangan (gap) indikator dalam dimensi usability, dimana dapat dilihat bahwa nilai selisih antara kualitas aktual (performance) dan kualitas ideal (importance) dari semua indikator bernilai negatif. Nilai selisih rata-rata gap sebesar -(0.10). Indikator yang memiliki gap terbesar adalah pada variabel USA7 yaitu "Mudah digunakan" dengan selisih gap sebesar -(0.15).

Sumber: Data primer yang diolah, Tahun 2018

Tabel diatas menunjukan nilai kesenjangan (gap) indikator dalam dimensi information, dimana dapat dilihat bahwa nilai selisih antara kualitas aktual (performance) dan kualitas ideal (importance) dari semua indikator bernilai negatif. Nilai selisih rata-rata gap sebesar -(0.08). Indikator yang memiliki gap terbesar adalah pada variabel INF3 yaitu "Informasi aktual" dengan selisih gap sebesar -(0.12).

Tabel 7 Nilai Gap Service Interaction

\begin{tabular}{cccc}
\hline & Kinerja & Harapan & GAP \\
\hline SERV1 & 4,84 & 4,89 & $-0,05$ \\
SERV2 & 4,61 & 4,64 & $-0,03$ \\
SERV3 & 4,56 & 4,63 & $-0,07$ \\
SERV4 & 4,38 & 4,41 & $-0,03$ \\
SERV5 & 2,18 & 3,81 & $-1,63$ \\
SERV6 & 2,53 & 4,09 & $-1,56$ \\
SERV7 & 4,61 & 4,63 & $-0,02$ \\
\hline Rata Rata & 3,96 & 4,44 & $-0,48$ \\
\hline Sumber:
\end{tabular}

Tabel diatas menunjukan nilai kesenjangan (gap) indikator dalam dimensi Service interaction, dimana dapat dilihat bahwa nilai selisih antara kualitas aktual (performance) dan kualitas ideal (importance) dari semua indikator bernilai negatif. Nilai selisih rata-rata gap sebesar -(0.48). Indikator yang memiliki gap terbesar adalah pada variabel SERV5 yaitu "Pelaksanaan layanan sesuai janji” dengan selisih gap sebesar $-(0.63)$.

Tabel 8 Nilai Kesenjangan Semua Indikator dengan Metode

\begin{tabular}{c|c|c|c}
\hline & Kinerja & Harapan & GAP \\
\hline Usability & 4,43 & 4,53 & $-0,10$ \\
Information & 4,45 & 4,53 & $-0,08$ \\
Service & 3,96 & 4,44 & $-0,48$ \\
Interaction & 4,28 & 4,50 & $-0,22$ \\
\hline Rata Rata & 4,2018
\end{tabular}

Nilai kesenjangan (gap) dari ketiga dimensi WEBQUAL secara keseluruhan memiliki nilai negatif. Nilai selisih rata-rata sebesar -(0.22). Dimensi yang memiliki gap terbesar adalah service interaction dengan selisih sebesar -(0.48). Hasil tersebut menunjukan nilai negatif atau $\mathrm{Q}<0$ yang berarti bahwa kualitas aktual saat ini masih belum dapat memenuhi kualitas ideal yang diinginkan pengguna, maka tingkat kualitas

Tabel 6 Nilai Gap Information

\begin{tabular}{c|c|c|c}
\hline & Kinerja & Harapan & GAP \\
\hline INF1 & 4,48 & 4,55 & $-0,07$ \\
INF2 & 4,66 & 4,74 & $-0,08$ \\
INF3 & 3,89 & 4,01 & $-0,12$ \\
INF4 & 4,41 & 4,5 & $-0,09$ \\
INF5 & 4,73 & 4,8 & $-0,07$ \\
INF6 & 4,66 & 4,73 & $-0,07$ \\
INF7 & 4,3 & 4,36 & $-0,06$ \\
\hline Rata Rata & 4,45 & 4,53 & $-0,08$ \\
\hline
\end{tabular}


dinyatakan masih buruk. Importance performance analysis (IPA) digunakan untuk melihat indikator kualitas website mana saja yang telah sesuai dengan keinginan pengguna dan mana saja yang membutuhkan perbaikan. Hasil dari analisis IPA menunjukan letak masing-masing indikator dalam dipertahankan. USA7, INF3, SERV5 dan SERV6 terletak pada kuadran III. Indikator-indikator ini dinilai sebagai indikator yang memiliki tingkat kepentingan rendah dan tingkat kinerjanya pun tidak terlalu dirasakan baik oleh pengguna. Indikator-indikator yang terletak dalam kuadran

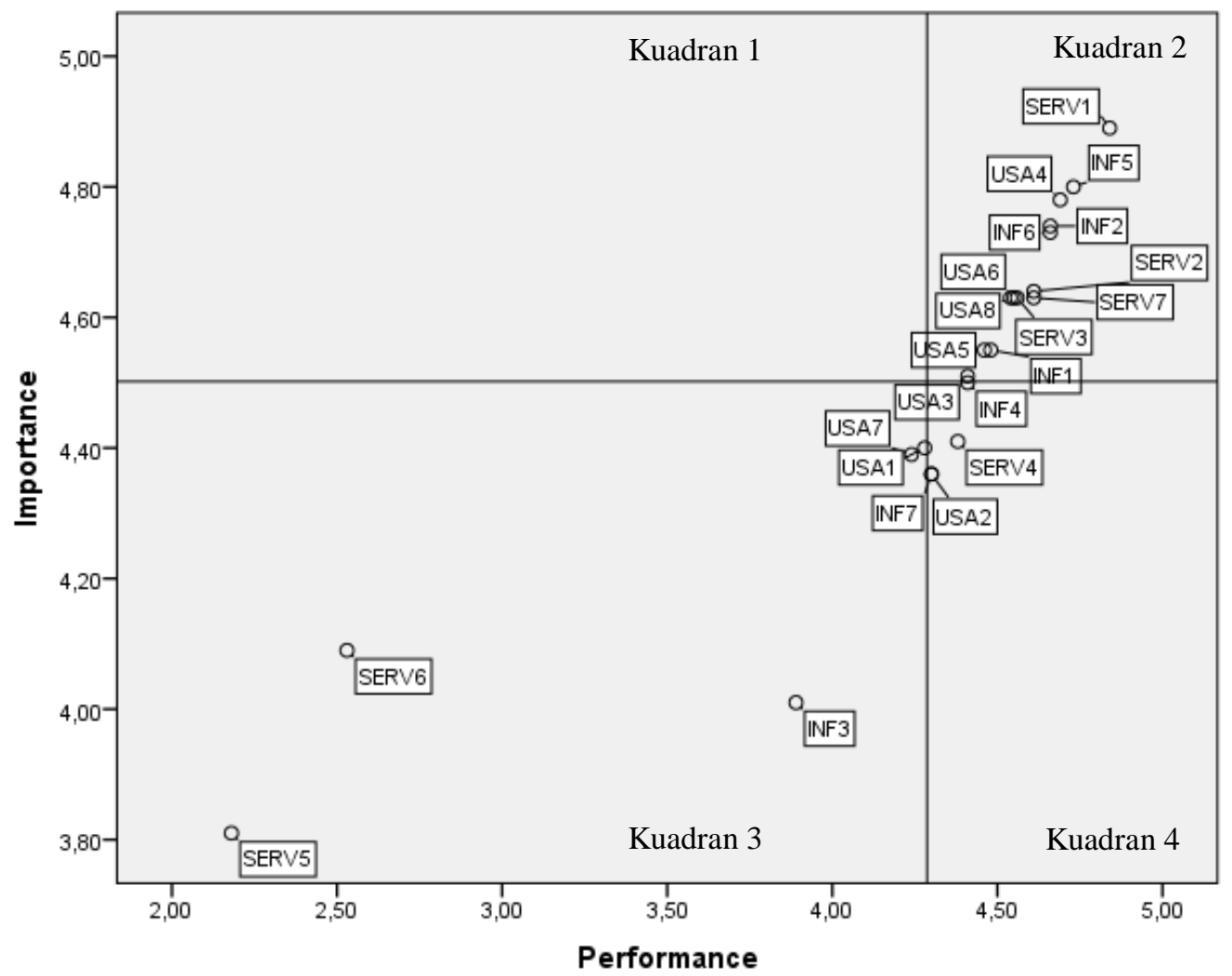

Gambar 8 Diagram Importance-Performance Analysis (IPA)

matrix IPA yang terdiri dari empat kuadran. Proses dalam menentukan kordinat untuk setiap indikator, menggunakan nilai rata-rata pembobotan indikator dari Tabel 4. Gambar 8 dibawah ini menunjukan posisi indikator dalam grafik matrix IPA, dimana masing- masing dimensi digambarkan dengan masing-masing label.

Berdasar posisi indikator dalam masing-masing kuadran dapat dilihat bahwa tidak terdapat indikator yang terletak dalam kuadran I, dimana hal ini berarti tidak terdapat indikator yang memiliki tingkat kepentingan yang tinggi namun tingkat kinerjanya dinilai rendah. Sehingga dapat disimpulkan bahwa tidak terdapat indikator dalam kuadran ini yang merupakan prioritas utama perbaikan. USA4, USA5, USA6, USA8, INF1, INF2, INF5, INF6, SERV1, SERV2, SERV3 dan SERV7 terletak pada kuadran II, dimana indikator ini dinilai sebagai indikator yang memiliki tingkat kepentingan tinggi dan tingkat kinerjanya pun sudah baik. Indikator-indikator yang terletak dalam kuadran ini adalah indikator yang sudah sesuai dengan keinginan pengguna dan harus ini adalah indikator yang dirasa cukup sesuai dan bukan merupakan prioritas utama perbaikan. Namun USA3 dan INF4 berada pada posisi yang berada ditengah- tengah kuadran II dan IV dan memiliki tingkat kepentingan tinggi dan tingkat kinerjanya sudah baik, serta memiliki tingkat kinerja yang rendah namun kinerja sudah dinyatakan baik oleh pengguna. SERV4 terletak pada kuadran IV dimana indikator-indikator ini dinilai memiliki tingkat kepentingan yang rendah namun tingkat kinerjanya sudah dinilai sangat baik oleh pengguna. Indikator-indikator ini adalah indikator yang dinilai telah jauh melampaui harapan pengguna dan bisa sedikit diabaikan. USA1,USA2 dan INF7 berada ditengah-tengah kuadran III dan IV sehingga dapat diartikan indikator ini memiliki performance yang tinggi dan tingkat importance yang sedang.

\subsection{Rekomendasi Perbaikan}

Dari hasil analisis kuadran IPA dapat dilihat atribut-atribut yang membutuhkan perbaikan kualitas yaitu atribut-atribut yang masuk dalam kuadran I dan kuadran III. Atribut-atribut pada 
kuadran tersebut memiliki tingkat kinerja yang rendah sehingga perlu dilakukan peningkatan kinerja terlebih lagi pada atribut kuadran I yang juga memiliki tingkat kepentingan yang tinggi. Tetapi hasil dari penelitian ini tidak terdapat atribut yang masuk dalam kuadran I, yang berarti hanya atribut pada kuadran III yang dipergunakan sebagai rekomendasi perbaikan untuk atributatribut tersebut berdasarkan dimensi webqual 4.0. Atribut yang termasuk dalam kuadran III diantaranya adalah USA7, INF3, SERV5 dan SERV6 yaitu :

1. Kemudahan penggunaan sistem

2. Informasi aktual / ketepatan waktu

3. Fitur untuk ruang komunitas

4. Fitur bagi pengguna untuk berkomunikasi dengan organisasi

Solusi yang akan diterapkan pada perbaikan sistem berdasarkan rekomendasi diantaranya adalah :

1. Mendesain ulang website dengan tampilan yang lebih dinamis, tampilan menu yang lebih teratur dan responsive

2. Meningkatkan manajemen pengelolaan data yang lebih baik

3. Menambahkan fitur forum bagi pengguna untuk berbagi informasi dan membahas topik tertentu

4. Menambahkan fitur chat dengan admin/pengelola website

\section{SIMPULAN}

Berdasarkan hasil penelitian dan analisis yang dilakukan pada website manajemen tugas akhir Jurusan Administrasi Bisnis Politeknik Negeri Banjarmasin menggunakan Webqual 4.0 dan Importance Performance Analysis, diperoleh kesimpulan sebagai berikut :

1. Hasil analisis kesesuaian terhadap website menghasilkan tingkat kesesuaian sebesar $95,22 \%$. Hal ini berarti bahwa tingkat kinerja dan layanan website manajemen tugas akhir jurusan Administrasi Bisnis Politeknik Negeri Banjarmasin masih berada dibawah ekspetasi pengguna.

2. Rata rata nilai kesenjangan (GAP) terhadap website manajemen tugas akhir Jurusan Administrasi Bisnis Politeknik Negeri Banjarmasin menunjukkan hasil yang negative $(<0)$ dengan nilai selisih rata-rata sebesar (0.22). Dimensi yang memiliki gap terbesar adalah service interaction dengan selisih sebesar -(0.48). Hasil tersebut menunjukan nilai negatif atau $Q<0$ yang berarti bahwa kualitas aktual saat ini masih belum dapat memenuhi kualitas ideal yang diinginkan pengguna, maka tingkat kualitas dinyatakan masih buruk.
3. Dari hasil analisis kuadran IPA dapat disimpulkan bahwa tidak terdapat indikator yang memiliki tingkat kepentingan yang tinggi namun tingkat kinerjanya dinilai rendah. Atribut yang memerlukan perbaikan berada dalam kuadran yang memiliki tingkat kepentingan yang rendah dan tingkat kinerja yang rendah, yaitu "kemudahan penggunaan sistem", "informasi aktual", "fitur untuk ruang komunitas" dan "fitur bagi pengguna untuk berkomunikasi dengan organisasi".

4. Berdasarkan hasil analisis dapat direkomendasikan 4 perbaikan yaitu mendesain ulang tampilan website, manajemen pengelolaan data, penambahan fitur forum dan fitur chat.

\subsection{Saran}

Saran untuk penelitian yang selanjutnya adalah :

1. Memanfaatkan metode lain untuk mendapatkan informasi tentang kekurangan website sehingga dapat diperoleh berbagai alternatif untuk perbaikan sistem.

2. Melakukan penelitian tidak hanya terbatas sampai analisis menggunakan Webqual 4.0 dan IPA, namun dikembangkan sampai dengan design interface.

3. Perlunya adanya penggabungan metode webqual 4.0 dengan metode lain agar memperoleh hasil analisa yang lebih detail lagi tentang kinerja suatu website.

\section{REFERENSI}

[1] Al Baiti, A. (2017). Pengukuran Kualitas Layanan Website Dinas Pendidikan Kota Malang Dengan Menggunakan Metode Webqual 4.0 Dan Importance And Performance Analysis (IPA)(Doctoral dissertation, Universitas Brawijaya).

[2] Astuti, A. P., \& Sari, P. K. (2016). Analisis Kualitas Website Lazada Indonesia Berdasarkan Metode Webqual 4.0 Dan Pengaruhnya Terhadap Kepuasan Pengguna. eProceedings of Management, 3(2).

[3] Chomeya, R. (2010). Quality of psychology test between Likert scale 5 and 6 points. Journal of Social Sciences, 6(3), 399-403.

[4] Santoso, B. S., Anwar, M. F., \& Hermawati, S. (2016). Analisis Kualitas Website Menggunakan Metode Webqual Dan Importance-Performance Analysis (IPA) Pada Situs Kaskus. In National Conference on Information Technology and Technical Engineering (CITEE). Yogyakarta: citee.

[5] Chaudhary, A. K., \& Warner, L. A. (2016). Identifying Gaps Between Importance And Satisfaction To Identify Extension Clients Needs.

[6] Delone, W. H., \& McLean, E. R. (2003). The DeLone and McLean model of information systems success: a ten-year update. Journal of management information systems, 19(4), 9-30. 
[7] Irawan, C. (2012). Evaluasi Kualitas Website Pemerintah Daerah Dengan Menggunakan WebQual (Studi Kasus Pada Kabupaten Ogan Ilir). Jurnal Sistem Informasi, 4(2).

[8] Juhanda, H., \& Sari, P. K. (2014). Analisis Kualitas Website Jalur Nugraha Ekakurir (JNE) Menggunakan Pendekatan Webqual dan Importance Performance Analysis (IPA) Menurut Persepsi Online Seller. eProceedings of Management, 1(3).

[9] Martilla, J. A., \& James, J. C. (1977). Importanceperformance analysis. The journal of marketing, 7779.

[10] Nistantya, G., Darwiyanto, E., \& Hidayati, H. (2015). Evaluasi Kualitas Website Digital Library Telkom University Menggunakan Metode Webqual 4.0 Dan Importance Performance Analysis. eProceedings of Engineering, 2(3).

[11] Pranoto, Y. A., Wibowo, S. A., \& Rokhman, M. M. (2018). EVALUASI KUALITAS LAYANAN WEBSITE MALANGSTRUDEL. COM MENGGUNAKAN TEKNIK PENGUKURAN WEBQUAL 4.0. Prosiding SENIATI, 4(1), 174179.

[12] Ranitaswari, P. A., Mulyani, S., \& Sadyasmara, C. A. B. (2018). ANALISIS KEPUASAN KONSUMEN TERHADAP KUALITAS PRODUK KOPI DAN KUALITAS PELAYANAN MENGGUNAKAN METODE IMPORTANCE PERFOMANCE ANALYSIS (Studi Kasus Di Geo Coffee). JURNAL REKAYASA DAN MANAJEMEN AGROINDUSTRI, 6(2), 147-157.

[13] Sanjaya, I. (2012). Pengukuran Kualitas layanan website kementerian kominfo dengan menggunakan metode webqual 4.0. Jurnal penelitian iptek-kom, 14(1), 1-14.

[14] Sastika, W. (2016). Analisis Pengaruh Kualitas Website (Webqual 4.0) terhadap Keputusan Pembelian pada Website E-Commerce Traveloka (Studi Kasus: Pengguna Traveloka di Kota Bandung Tahun 2015). Nasional Dalam Rangka Menghadapi Persaingan Global" Malang, 17 Mei.

[15] Seng Wong, M., Hideki, N., \& George, P. (2011). The use of importance-performance analysis (IPA) in evaluating Japan's e-government services. Journal of Theoretical and Applied Electronic Commerce Research, 6(2), 17-30.

[16] Setyorini, A. (2016). Analisa Pengukuran Kualitas Layanan Website Fakultas Teknik Universitas Janabadra Menggunakan Metode Webqual. Informasi Interaktif, 1(1), 26-33 
JUST TI, Volume 11 Nomor 1, Januari 2019: 16-23 